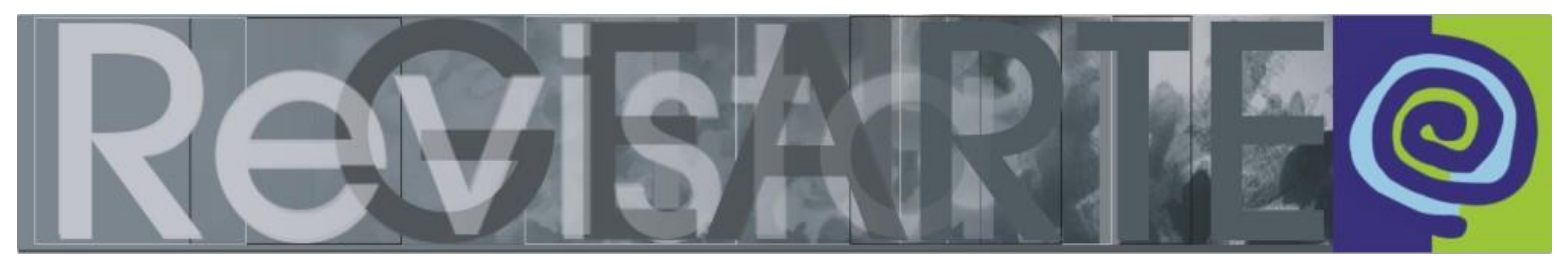

Volume 1, Número 2, Agosto/2014, ISSN 2357-9854

\title{
Mediação em Artes Visuais
}

A mediação em artes visuais é um tema que interessa a todos que trabalham com educação e arte e também com outras disciplinas que dialogam com a produção artística, o que inclui a reflexão e a discussão sobre questões das mais diversas áreas. Essa reflexão se faz na tessitura entre práticas, atitude investigativa e pesquisa, a partir do que poderão se desdobrar sempre novas possibilidades de pensar e vivenciar a mediação.

Este número da Revista GEARTE pretende ampliar a reflexão sobre o tema, ao trazer a contribuição de importantes pesquisadores e professores que, através de diferentes aportes, nos provocam a estabelecer outras relações e abrem novos diálogos sobre mediação, educação e aprendizagem em artes visuais. Os espaços onde pode ocorrer a mediação são diversos, entre escolas, museus, instituições culturais e outros lugares que oportunizam o contato com proposições artísticas. Alguns dos autores deste número se debruçam sobre diversas possibilidades para públicos distintos.

Uma questão importante na discussão sobre a relação entre mediação e aprendizagem é o papel-chave da interpretação. Para compreender uma imagem é necessário interpretá-la. Esta competência estará sempre vinculada à pessoa que a interpreta e a um contexto cultural. O artigo "Visual Metaphors: meaning, interpretation and culture" de Michael Parsons traz elementos da teoria da cognição incorporada para pensar sobre a utilização de metáforas em imagens visuais, relacionadas tanto ao seu contexto de produção como ao exercício da interpretação e produção de sentido para as imagens.

Em "Mediações culturais e contaminações estéticas" Mirian Celeste Martins nos convida a pensar sobre o conceito de mediação em diálogo com a cultura, como a proposição de encontros significativos com a arte, seja na escola ou em espaços expositivos. A autora aborda uma das dimensões do grande continente da mediação 
a partir dos estudos realizados junto ao Grupo de Pesquisa Mediação Cultural: contaminações e provocações estéticas, que coordena. Problematiza as diferenças entre a função e a ação do mediador, bem como entre os conceitos de apresentação, explicação, interpretação, conhecimento teórico, informação e mediação cultural, e nos instiga a provocar experiências de contaminação estética.

José Minerini Neto no artigo "A origem de projetos educacionais nas Bienais de Arte de São Paulo" traz uma valiosa perspectiva histórica sobre a educação em espaços expositivos, abordando o surgimento da ação educativa na Bienal. Retomando algumas das situações e práticas iniciais para organização de um projeto educacional - a partir da constatação de sua ausência na primeira Bienal, de 1951 apresenta e analisa dados sobre quem orientou, quem participou e como foram concebidos os primeiros projetos de ação educativa nesse contexto.

Outro aspecto importante a considerar no contexto da mediação, seja em espaços expositivos de artes visuais ou na sala de aula e em outros espaços educativos, é a necessidade de se refletir sobre abordagens apropriadas para diferentes tipos de produções artísticas. O artigo "Mediação em museus e em exposições: espaços de aprendizagem sobre arte e seu sistema" de Denise Grinspum propõe pensarmos nas diferenças entre possibilidades didáticas para o encontro com arte moderna e arte contemporânea na mediação. Defende a importância da compreensão do sistema da arte na contemporaneidade, ressaltando as dificuldades que emergem no contexto de sua mediação.

O texto "Mediação cultural como possibilidade de aprendizagem na infância" de Silvia Sell Duarte Pillotto e Letícia Ribas Diefenthaeler Bonh reflete sobre a mediação em espaços formais e não formais de ensino para os aprendizes da educação infantil. Enfatiza a necessidade de acesso a espaços de exposição pelas crianças pequenas, a partir do diálogo entre escola e espaços culturais. A pesquisa se fundamenta na relação entre mediação cultural e aprendizagem, abordando alguns conceitos que embasam as práticas no contato entre a criança, o educador de museus e o professor.

Ainda no contexto de educação em instituições museais, Adriana Ganzer e Maria Isabel Leite - em "Encontros da Arte e do Museu com a Educação: momentos de encantamento e reflexão" - abordam os resultados de uma pesquisa sobre 
relações entre memória, descobertas e narrativas que permeiam o museu como espaço de produção de conhecimento. Discutem sobre as relações entre espaço formal e não formal de educação, pensando na construção e desconstrução da visita mediada em espaços expositivos, e apresentam algumas experiências estéticas ocorridas na relação entre crianças, adultos, espaço museal, social e patrimônio.

O texto "O 'pulo do gato' e a mediação em arte: possibilidades de interação" de Marília Forgearini Nunes nos lembra que somos seres constituídos pela linguagem e é através dela que damos sentido às experiências e ao nosso entorno. A autora, no texto, faz a mediação da leitura de um livro que auxiliará a pensar a própria mediação como experiência produtora de sentido. Trata-se do livro Pula, gato!, de Marilda Castanha, em que uma narrativa imagética mostra modos de interação com a arte e nos ajuda a pensar num fazer mediador que amplie a compreensão da arte e de seus objetos. Uma das ideias-chave desse texto é conceber o ato de mediar como um ato engenhoso - associado à expressão pulo do gato.

No instigante depoimento verbovisual "Entre obras", a artista e professora Dra. Ana Amália Barbosa comenta ações de mediação realizadas com seus alunos cadeirantes - a maioria tetraplégicos e mudos, com paralisia cerebral. Aborda o contexto em que desenvolve o trabalho, mostrando, por meio de uma narrativa verbal e imagética, as visitas realizadas desde 2009 a diferentes espaços expositivos da cidade de São Paulo (SP), incluindo o Instituto Tomie Ohtake, o SESC Pompeia, o Jardim das Esculturas no Parque da Luz, o Museu de Arte Moderna no Parque Ibirapuera, o Centro Cultural do Banco do Brasil (CCBB-SP), a Galeria do Instituto de Artes da Universidade Estadual Paulista (UNESP) e o Memorial da América Latina. Tais ações envolvem um trabalho de preparação e se desdobram em outras atividades após as visitas. A autora ressalta as aprendizagens realizadas a partir dessas experiências.

Na seção Ensaio Visual, o vídeo de Mário Linhares tem o poder de nos revelar uma experiência de mediação vivida - pelo autor e por sua companheira, Ketta Cabral Linhares - em um povoado da Costa do Marfim, África. Ao desenhar as pessoas, suas casas, seus objetos, suas práticas sociais, enfim o cotidiano da pequena vila, o casal transformava o desenho em instrumento e, ao mesmo tempo, objeto de mediação; mediação essa na qual experiências de arte e de vida tornavam-se inseparáveis. 0 
vídeo apresenta, poeticamente, os cadernos de viagem produzidos nesse encontro entre culturas. As imagens da capa deste número da Revista são oriundas desses cadernos.

Andrea Hofstaetter, Gabriela Bon e Marília Forgearini Nunes (Organizadoras) 